\title{
Innovative interstellar explorer
}

\author{
Ralph L McNutt Jr ${ }^{1}$, Robert E Gold ${ }^{1}$, Tom Krimigis ${ }^{1}$, Edmond C Roelof ${ }^{1}$, Mike \\ Gruntman $^{2}$, George Gloeckler ${ }^{3}$, Patrick L Koehn ${ }^{3}$, William S Kurth ${ }^{4}$, Steven R \\ Oleson $^{5}$, Douglas I Fiehler ${ }^{6}$, Mihaly Horanyi ${ }^{7}$, Richard A Mewaldt ${ }^{8}$, James C \\ Leary $^{1}$, Brian J Anderson ${ }^{1}$ \\ ${ }^{1}$ Johns Hopkins University Applied Physics Laboratory, 11100 Johns Hopkins Road, \\ Laurel, MD 20723-6099, United States \\ ${ }^{2}$ University of Southern California, Astronautics and Space Technology Division, Rapp Research Building 230, \\ Los Angeles, CA 90089-1192, United States \\ ${ }^{3}$ University of Michigan, 2455 Hayward, Ann Arbor, MI 48109-2143, United States \\ ${ }^{4}$ The University of Iowa, 203 Van Allen Hall, Iowa City, IA 52242-1479, United States \\ ${ }^{5}$ NASA Glenn Research Center, 21000 Brookpark Road, Cleveland, OH 44135, United States \\ ${ }^{6}$ QSS Group, Inc., NASA Glenn Research Center, 21000 Brookpark Road, Cleveland, OH 44135, United States \\ ${ }^{7}$ Laboratory for Atmospheric and Space Physics and Department of Physics, University of Colorado at Boulder, \\ Boulder, CO 80309-0392, United States \\ ${ }^{8}$ California Institute of Technology, 220-47 Downs Laboratory, Pasadena, CA 91126, United States
}

\begin{abstract}
An interstellar "precursor" mission has been under discussion in the scientific community for at least 30 years. Fundamental scientific questions about the interaction of the Sun with the interstellar medium can only be answered with in situ measurements that such a mission can provide. The Innovative Interstellar Explorer (IIE) and its use of Radioisotope Electric Propulsion (REP) is being studied under a NASA "Vision Mission" grant. Speed is provided by a combination of a high-energy launch, using current launch vehicle technology, a Jupiter gravity assist, and long-term, low-thrust, continuous acceleration provided by an ion thruster running off electricity provided by advanced radioisotope electric generators. A payload of ten instruments with an aggregate mass of $\sim 35 \mathrm{~kg}$ and requiring $\sim 30 \mathrm{~W}$ has been carefully chosen to address the compelling science questions. The nominal 20-day launch window opens on 22 October 2014 followed by a Jupiter gravity assist on 5 February 2016. The REP system accelerates the spacecraft to a "burnout" speed of 7.8 AU per year at $104 \mathrm{AU}$ on 13 October 2032 (Voyager 1's current speed is $\sim 3.6 \mathrm{AU} / \mathrm{yr}$ ). The spacecraft will return at least 500 bits per second from at least $200 \mathrm{AU} \sim 30$ years after launch. Additional (backup) launch opportunities occur every 13 months to early 2018. In addition to addressing basic heliospheric science, the mission will ensure continued information on the far-heliospheric galactic cosmic ray population after the Voyagers have fallen silent and as the era of human Mars exploration begins.
\end{abstract}

\section{INTRODUCTION}

The Innovative Interstellar Explorer (IIE) study [1-6] is one of several "Vision Missions" funded by NASA for studying in more detail missions that have been deferred in various strategy documents due to technical complexity. In particular, the idea of an "interstellar precursor mission" has been advocated in a variety of NASA and National Academy of Science documents for at least 30 years (Table 1).

Any robotic deep-space mission requires four elements: (1) compelling science, i.e., the rationale for the mission, (2) appropriate and developed enabling technologies, i.e., the means to implementation, (3) a strategy, i.e., advocacy by all current and potential stakeholders in the mission, and (4) programmatics, i.e., a "new start" in the U.S. Federal budget for NASA, with appropriate funds for development and implementation in the out-years and a plan for years after years further out in the planning process, as applicable to a given missions. A well-thought-out approach with all of these key elements is required to promote and accomplish a successful science exploration plan.

CP 858, Physics of the Inner Heliosheath,

edited by J. Heerikhuisen, V. Florinski, G. P. Zank, and N. V. Pogorelov

(C) 2006 American Institute of Physics 978-0-7354-0355-0/06/\$23.00 
Table 1. Sample Listing of Reports Calling for an Interstellar Probe

\begin{tabular}{|c|c|}
\hline NASA Studies & National Academy Studies \\
\hline Outlook for Space, 1976 & $\begin{array}{l}\text { Physics through the } 1990 \text { 's - Panel on Gravitation, } \\
\text { Cosmology, and Cosmic Rays (D. T. Wilkinson, } \\
\text { chair), } 1986 \text { NRC report }\end{array}$ \\
\hline $\begin{array}{l}\text { An implementation plan for solar system space physics, S. } \\
\text { M. Krimigis, chair, } 1985\end{array}$ & $\begin{array}{l}\text { Solar and Space Physics Task Group Report (F. Scarf, } \\
\text { chair),1988 NRC study Space Science in the } 21 \text { st } \\
\text { Century - Imperatives for the Decade } 1995-2015\end{array}$ \\
\hline $\begin{array}{ccc}\text { Space } & \text { Physics } & \text { Strategy-Implementation } \\
\text { NASA Space Physics Program for 1995-2010 } & \text { The }\end{array}$ & $\begin{array}{l}\text { Astronomy and Astrophysics Task Group Report (B. } \\
\text { Burke, chair), } 1988 \text { NRC study Space Science in } \\
\text { the } 21 \text { st Century - Imperatives for the Decade } \\
1995-2015\end{array}$ \\
\hline Sun-Earth Connection Technology Roadmap, 1997 & $\begin{array}{l}\text { The Decade of Discovery in Astronomy and Astrophysics } \\
\text { (John N. Bahcall, chair) }\end{array}$ \\
\hline 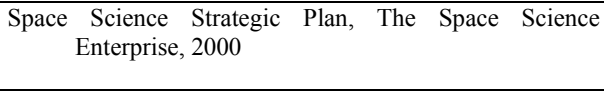 & $\begin{array}{c}\text { The Committee on Cosmic Ray Physics of the NRC Board } \\
\text { on Physics and Astronomy (T. K. Gaisser, chair), } \\
1995 \text { report Opportunities in Cosmic Ray Physics }\end{array}$ \\
\hline Sun-Earth Connection Roadmaps, 1997, 2000, 2003 & $\begin{array}{l}\text { A Science Strategy for Space Physics, Space Studies } \\
\text { Board, NRC, National Academy Press, } 1995 \text { (M. } \\
\text { Negebauer, chair) }\end{array}$ \\
\hline NASA 2003 Strategic Plan & $\begin{array}{l}\text { The Sun to the Earth -and Beyond: A Decadal Research } \\
\text { Strategy in Solar and Space Physics }\end{array}$ \\
\hline
\end{tabular}

For this mission concept, we have adopted a science formulation with appropriate instrumentation as vetted by the heliospheric science community over the years in general, and by our team in particular. We have identified the enabling technology, here radioisotope electric propulsion (REP) combined with advanced radioisotope power sources (RPS), with existing technologies. The goal of this approach is to provide a credible technological implementation while minimizing required technical innovations with their associated costs for both development and space-flight qualification.

Within these bounds, IIE is still "visionary" in the sense of reaching farther and faster than all previous excursions into space. At the same time, we believe the mission to be doable while representing one more of a long line of "firsts" adopted into the "banner" for the mission [6] that includes: The "all-seeing eye" with the visionary motto "Novus Ordo Seclorum" ("The new order of the ages"); the Pleiades - or "Seven Sisters" Messier 45; 425 L.Y; "If you seek our future, look to the stars" (Latin - cf. C. Wren); the Montgolfier brothers hot air balloon flight, Paris; 4 June 1783; Robert Goddard's liquid fueled roclet, 16 March 1926; the Wright Brothers first flight, 17 Dec 1903; Explorer I, the first U.S. orbital satellite, 1 February 1958 with Pickering, Van Allen, Von Braun; Pioneer 10 at Jupiter flyby, 3 Dec 1973; and Voyager 1 and 2, both launched in 1977.

\section{THE FIRST TRUE STAR SHIP}

Recently, the Voyager 1 spacecraft has returned data from the termination shock of the solar wind at a heliocentric distance of $94 \mathrm{AU}$ [7-11]. Beyond the shock is the heliopause, the pressurebalance interface between the plasma components of the solar wind and of the interstellar medium. Beyond that interface there may be an external shock before one reaches the "undisturbed" interstellar medium, but the properties of the interstellar medium remain elusive [12-13]. To measure the properties of the VLISM, especially the magnetic field and low-energy cosmic rays, in situ sampling is required. 
Many formulations of a science rationale have been made for an "interstellar precursor" mission that would probe the nearby interstellar medium [14-20]. In this NASA-supported Vision Mission study, we consider the implementation of a scientifically compelling precursor mission to the interstellar medium. Dubbed the Innovative Interstellar Explorer (IIE), the mission concept combines a compact payload, $\sim 1000-\mathrm{kg}$ (wet) class satellite, high launch energy, and electric propulsion. Four options are studied that combine various levels of risk and technical readiness for implementing this mission. Although not the first probe to escape the gravitational pull of the Sun, this would be the first mission for which the material between the stars is the destination. IIE will be bound for the stars, acquiring data on local interstellar conditions as long as it can. In this sense it really will be the first Star Ship.

\section{Science Questions and Required Instruments}

Four principal science questions are addressed. These are addressed by a set of ten carefully selected science instruments, listed with estimates of their required resources in Table 2. Detailed performance characteristics are given in the references [4,6]. How these trace through science objectives to science results are described in the traceability matrix [4,6], summarized in Table 3 . The science questions are traced back to the third meeting of the Interstellar Probe Science and Technology Definition Team (IPSTDT) meeting held at the Jet Propulsion Laboratory (JPL).

Table 2. Instruments and Resource Estimates

\begin{tabular}{|c|c|c|c|c|}
\hline Acronym & Instrument & $\begin{array}{c}\text { Mass } \\
(\mathrm{kg})\end{array}$ & $\begin{array}{l}\text { Power } \\
\text { (W) }\end{array}$ & $\begin{array}{c}\text { Average acquisition } \\
\text { data rate (bps) }\end{array}$ \\
\hline MAG & Magnetometer & 8.81 & 5.30 & 130.00 \\
\hline PWS & Plasma wave sensor & 10.00 & 1.60 & 65.00 \\
\hline PLS & Plasma & 2.00 & 2.30 & 10.00 \\
\hline EPS & Energetic particle spectrometer & 1.50 & 2.50 & 10.00 \\
\hline $\begin{array}{ll}\mathrm{CRS} & - \\
\mathrm{ACR} / \mathrm{GCR}\end{array}$ & $\begin{array}{l}\text { Cosmic-ray spectrometer: anomalous and } \\
\text { galactic cosmic rays }\end{array}$ & 3.50 & 2.50 & 5.00 \\
\hline CRS - LoZCR & $\begin{array}{l}\text { Cosmic-ray spectrometer: } \\
\text { electrons/positrons, protons, helium }\end{array}$ & 2.30 & 2.00 & 3.00 \\
\hline CDS & Cosmic dust sensor & 1.75 & 5.00 & 0.05 \\
\hline NAI & Neutral atom detector & 2.50 & 4.00 & 1.00 \\
\hline ENA & Energetic neutral atom imager & 2.50 & 4.00 & 1.00 \\
\hline LAD & Lyman-alpha detector & 0.30 & 0.20 & 1.00 \\
\hline $\begin{array}{c}\text { Total } \\
\text { resources }\end{array}$ & & 35.16 & 29.40 & 226.05 \\
\hline
\end{tabular}

The additional instrument whose inclusion has been debated, is an infrared telescope capable of looking back toward the Sun to assess the solar system dust that causes IR extinction as we look outward from Earth. While such observations are important for understanding the structure of the solar system and this platform would provide a unique perspective from which to make such measurements, the required resources (mass, power) exceed what is available. We have judged the additional measurements to be worthwhile but below the science floor for the mission; hence, this instrument is not included in the baseline presented here. The corresponding questions, instrument, and analysis product are shown in light grey boxes in Table 3 . 
Table 3. Short Version of the Traceability Matrix

\begin{tabular}{|c|c|c|c|c|}
\hline \multirow{2}{*}{ 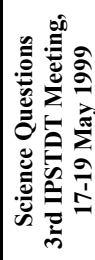 } & \multirow[b]{2}{*}{ From NASA's IPSTDT Report } & $\begin{array}{c}\text { Required } \\
\text { Instruments }\end{array}$ & $\begin{array}{l}\text { Analysis } \\
\text { Product } \\
\end{array}$ & $\begin{array}{c}\text { Science } \\
\text { Result }\end{array}$ \\
\hline & & \multicolumn{3}{|c|}{ THIS WORK } \\
\hline \multirow{8}{*}{ 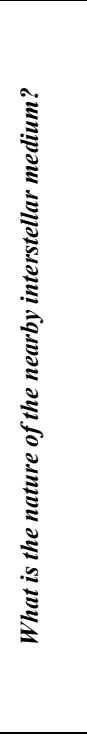 } & $\begin{array}{l}\text { How does the composition of interstellar matter } \\
\text { differ from that of the solar system? }\end{array}$ & $\begin{array}{l}\text { PLS, } \\
\text { EPS, } \\
\text { CRS }\end{array}$ & \multirow{3}{*}{$\begin{array}{l}\text { Interstellar medium } \\
\text { composition }\end{array}$} & \multirow{3}{*}{ 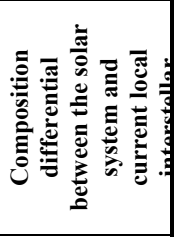 } \\
\hline & $\begin{array}{l}\text { What constraints do the interstellar abundances of }{ }^{2} \mathrm{H} \\
\text { and }{ }^{3} \mathrm{He} \text { place on Big Bang and chemical evolution } \\
\text { theories? }\end{array}$ & $\begin{array}{l}\text { CRS - } \\
\text { LoZCR }\end{array}$ & & \\
\hline & $\begin{array}{l}\text { Is there evidence for recent nucleosynthesis in the } \\
\text { interstellar medium? }\end{array}$ & CRS & & \\
\hline & $\begin{array}{l}\text { What is the density, temperature, and ionization state } \\
\text { of the interstellar gas, and the strength and direction } \\
\text { of the interstellar magnetic field? }\end{array}$ & $\begin{array}{l}\text { MAG, } \\
\text { PLS }\end{array}$ & $\begin{array}{l}\text { Thermodynamic and } \\
\text { physical state of the } \\
\text { very local interstellar } \\
\text { medium (VLISM) }\end{array}$ & \multirow{5}{*}{ 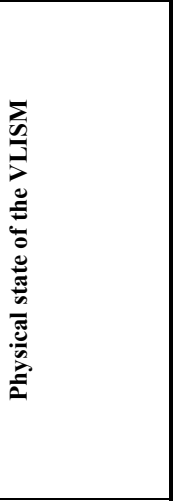 } \\
\hline & $\begin{array}{l}\text { What processes control the ionization state, heating, } \\
\text { and dynamics of the interstellar medium? }\end{array}$ & $\begin{array}{l}\text { PLS, } \\
\text { LAD, } \\
\text { NAI, } \\
\text { ENA }\end{array}$ & $\begin{array}{l}\text { Energy inputs in the } \\
\text { VLISM }\end{array}$ & \\
\hline & $\begin{array}{l}\text { How much interstellar matter is in the form of dust } \\
\text { and where did it originate? }\end{array}$ & \begin{tabular}{|l|} 
CDS, \\
(PWS), \\
PLS
\end{tabular} & $\begin{array}{l}\text { Neutral matter assay } \\
\text { for the VLISM }\end{array}$ & \\
\hline & $\begin{array}{l}\text { How much greater are cosmic ray nuclei and electron } \\
\text { intensities outside the heliosphere, and what is their } \\
\text { relation to galactic gamma ray and radio emission? }\end{array}$ & $\begin{array}{l}\text { CRS, } \\
\text { PWS }\end{array}$ & $\begin{array}{l}\text { Low-energy galactic } \\
\text { cosmic rays }\end{array}$ & \\
\hline & $\begin{array}{l}\text { What spectrum of } 10-100 \text { micron galactic infrared } \\
\text { and Cosmic Infrared Background Radiation is hidden } \\
\text { by emission from the zodiacal dust? }\end{array}$ & $\begin{array}{l}\text { Not } \\
\text { measured }\end{array}$ & $\begin{array}{l}\text { IR absorption by } \\
\text { solar system dust }\end{array}$ & \\
\hline \multirow{5}{*}{ 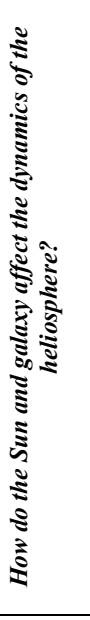 } & What is the size and structure of the heliosphere? & $\begin{array}{l}\text { MAG, } \\
\text { PWS, } \\
\text { PLS, } \\
\text { EPS, } \\
\text { LAD, } \\
\text { ENA } \\
\end{array}$ & $\begin{array}{l}\text { Heliospheric spatial } \\
\text { scales }\end{array}$ & \multirow{2}{*}{ 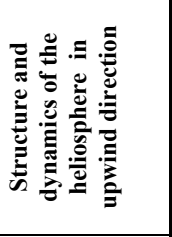 } \\
\hline & $\begin{array}{l}\text { How do the termination shock and heliopause } \\
\text { respond to solar variations and interstellar pressure? }\end{array}$ & $\begin{array}{l}\text { MAG, } \\
\text { PLS }\end{array}$ & $\begin{array}{l}\text { Heliospheric } \\
\text { temporal variably }\end{array}$ & \\
\hline & $\begin{array}{l}\text { How does the interstellar medium affect the inner } \\
\text { heliosphere and solar wind dynamics? }\end{array}$ & $\begin{array}{l}\text { PLS, } \\
\text { EPS, } \\
\text { CRS }\end{array}$ & $\begin{array}{l}\text { Spatial and temporal } \\
\text { variability of the } \\
\text { interstellar medium } \\
\text { properties }\end{array}$ & \multirow{3}{*}{ 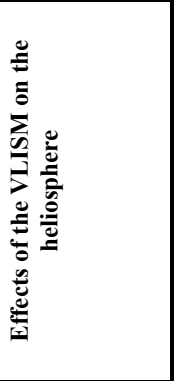 } \\
\hline & $\begin{array}{l}\text { What roles do thermal plasma, pickup ions, waves, } \\
\text { and anomalous cosmic rays play in determining the } \\
\text { structure of the termination shock? }\end{array}$ & \begin{tabular}{|l|} 
PLS, \\
EPS, \\
PWS, \\
CRS \\
AGCR \\
\end{tabular} & $\begin{array}{l}\text { Inputs from } \\
\text { heliospheric } \\
\text { interaction into the } \\
\text { solar wind }\end{array}$ & \\
\hline & $\begin{array}{l}\text { What are the properties of interstellar gas and dust } \\
\text { that penetrate into the heliosphere? }\end{array}$ & $\begin{array}{l}\text { NAI, } \\
\text { ENA, } \\
\text { CDS }\end{array}$ & $\begin{array}{l}\text { Properties } \\
\text { interstellar gas and } \\
\text { dust in the outer } \\
\text { heliosphere }\end{array}$ & \\
\hline
\end{tabular}




\begin{tabular}{|c|c|c|c|c|}
\hline \multirow{4}{*}{ 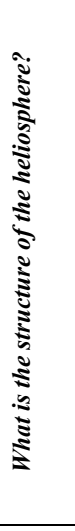 } & $\begin{array}{l}\text { Does the heliosphere create a bow shock in the } \\
\text { interstellar medium? }\end{array}$ & $\begin{array}{l}\text { MAG, } \\
\text { PWS, } \\
\text { PLS }\end{array}$ & $\begin{array}{l}\text { Determination of } \\
\text { whether the solar } \\
\text { system produces an } \\
\text { external shock }\end{array}$ & \multirow{4}{*}{ 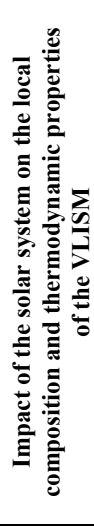 } \\
\hline & $\begin{array}{l}\text { What is the relation of the hydrogen wall outside the } \\
\text { heliopause to similar structures and winds observed } \\
\text { in neighboring systems? }\end{array}$ & $\begin{array}{l}\text { NAI, } \\
\text { ENA, } \\
\text { PLS }\end{array}$ & $\begin{array}{l}\text { Structure } \\
\text { properties of the } \\
\text { predicted hydrogen } \\
\text { wall }\end{array}$ & \\
\hline & $\begin{array}{l}\text { How do the Sun and heliosphere influence the } \\
\text { temperature, ionization state, and energetic particle } \\
\text { environment of the local interstellar medium? How } \\
\text { far does the influence extend? }\end{array}$ & $\begin{array}{l}\text { NAI, } \\
\text { ENA, } \\
\text { PLS, } \\
\text { EPS, } \\
\text { CRS } \\
\end{array}$ & $\begin{array}{l}\text { Penetration of } \\
\text { heliosheath properties } \\
\text { into the VLISM }\end{array}$ & \\
\hline & $\begin{array}{l}\text { How does particle acceleration occur at the } \\
\text { termination shock and at other astrophysical shocks? }\end{array}$ & $\begin{array}{l}\text { PLS, } \\
\text { EPS, } \\
\text { CRS - } \\
\text { Autonom } \\
\text { ous burst }\end{array}$ & $\begin{array}{l}\text { Characterization of } \\
\text { particle acceleration } \\
\text { at the termination } \\
\text { shock }\end{array}$ & \\
\hline \multirow{4}{*}{ 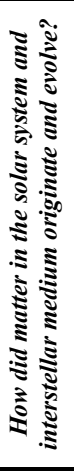 } & $\begin{array}{l}\text { Is there structure in the Zodiacal cloud due to } \\
\text { dynamical processes associated with solar activity, } \\
\text { planets, asteroids, comets, and Kuiper Belt objects? }\end{array}$ & $\begin{array}{l}\text { PLS, } \\
\text { CDS, } \\
(\text { PWS })\end{array}$ & \multirow{2}{*}{$\begin{array}{l}\text { Structure } \\
\text { dynamics of the } \\
\text { Zodiacal dust cloud } \\
\text { in the outer } \\
\text { heliosphere }\end{array}$} & \multirow{4}{*}{ 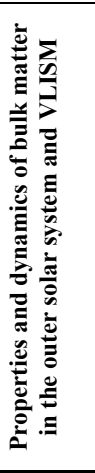 } \\
\hline & $\begin{array}{l}\text { What does the distribution of small Kuiper Belt } \\
\text { objects and dust tell us about the formation of the } \\
\text { solar system? }\end{array}$ & $\begin{array}{l}\text { CDS, } \\
\text { PLS, } \\
\text { EPS, } \\
\text { (PWS) }\end{array}$ & & \\
\hline & $\begin{array}{l}\text { How does the structure of the Zodiacal dust cloud } \\
\text { impact infrared observations of the galaxy and } \\
\text { searches for planets around other stars? }\end{array}$ & $\begin{array}{l}\text { Not } \\
\text { measured }\end{array}$ & $\begin{array}{l}\text { Quantified extinction } \\
\text { from Zodiacal dust }\end{array}$ & \\
\hline & $\begin{array}{l}\text { What are the origin, nature, and distribution of } \\
\text { organic matter in the outer solar system and the } \\
\text { interstellar medium? }\end{array}$ & $\begin{array}{l}\text { CDS, } \\
\text { PLS, } \\
\text { EPS, } \\
\text { (PWS) }\end{array}$ & $\begin{array}{l}\text { Identification of in } \\
\text { situ organic materials } \\
\text { or fragments in the } \\
\text { heliospheric } \\
\text { boundary regions } \\
\text { and/or VLISM }\end{array}$ & \\
\hline
\end{tabular}

\section{THE SPACECRAFT}

The baseline IIE spacecraft is a spinner using low-mass RTGs and a 1-kW ion engine that uses xenon propellant, an approach referred to as radioisotope electric propulsion (REP) [21]. A conceptual design based upon one of the technology options studied is shown in Figure 1. Key to the approach (as with solar sail approaches [19]) is keeping the mass of all components as low as their required functionality allows.

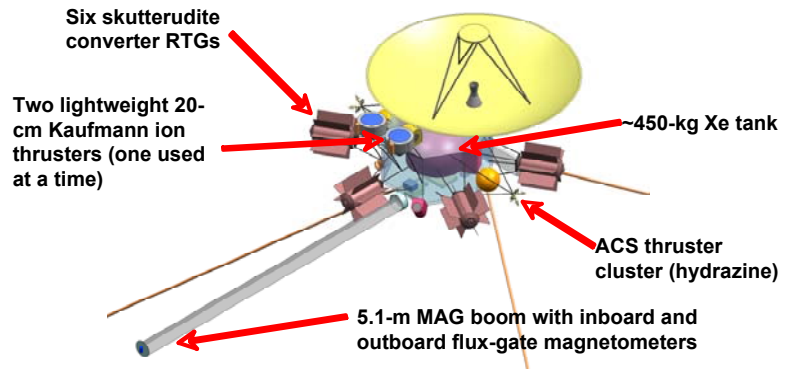

Figure 1. A concept for the IIE spacecraft. Technology Option 2 is shown. Option 1 baselined for flight has three ion engines (two plus a space and a slightly smaller high gain antenna (HGA) with a 2.1-m diameter. 


\section{Baseline Mission}

The baseline mission was chosen following multiple mission design and spacecraft technology iterations with JPL's Team-X. All missions studied travel to an aim-point within $20^{\circ}$ of the incoming interstellar wind direction by traveling outward from the Earth without Venus, Earth, or Mars gravity assists. A variety of mission scenarios were studied [22]. A Jupiter gravity assist was chosen as the baseline mission design. This design was iterated further as the spacecraft concept matured. Four technology options were devised with corresponding masses and power modes. For each a $30 \%$ mass contingency was added and the mission design reoptimized. Option 1, with the lowest level of new technology and selected as the baseline, reaches $200 \mathrm{AU}$ in just over 30 years with an asymptotic speed of $\sim 7.8 \mathrm{AU} / \mathrm{yr}$ (just over twice that of Voyager 1). Each option has a $\sim 20$ day launch window. Backups occur at $\sim 13$-month intervals (Nov. 2015, Dec. 2016, Jan. 2018) with the same spacecraft (and increasing flyout time to $200 \mathrm{AU}$ ), and the cycle repeats about every 12 years (Jupiter's orbital period) with the best opportunities in 2014, 2026, 2038, and 2050.

\section{INTERSTELLAR PROBE AND HUMAN EXPLORATION}

Solar energetic particle (SEP) events and galactic cosmic rays (GCRs) present a radiation threat to human explorers living and working outside low-Earth orbit. SEP events can be warned against and tend to occur near solar maximum. These solar outbursts help "tangle" the interplanetary magnetic field, decreasing the flux of GCRs penetrating into the heliosphere. The GCRs, especially those with heavy nuclei, cannot easily be shielded against. Current thinking suggests that GCR variability is controlled by solar activity. However, without actually reaching near-interstellar space and sampling the undisturbed GCR spectra, we cannot know for certain whether large investments in human infrastructure are appropriately designed for dealing with this potential hazard to human exploration of the solar system.

\section{SUMMARY}

The IIE is an exciting mission of exploration, discovery, and understanding. Primary issues are low-mass radioisotope power supplies, long-lived and low-power electric propulsion engines, communications infrastructure on the ground, available expendable launch vehicles with highenergy upper stages, and parts and subsystems that can be qualified for $30+$ year missions. While all of these issues need attention and resources, implementation of the baseline mission for a launch in 2014 is possible as long as the serious planning starts now [23]:

"The real journey will occur when we embark on an interstellar probe, with sufficient instrumentation and the capability to rapidly access the distant heliosphere. This journey will be one of the great explorations of humankind, when we leave the safety of our solar system and venture forth into interstellar space."

\section{ACKNOWLEDGMENTS}

This work was supported by NASA Vision Mission grant NNG04GJ60G. We acknowledge contributions of the NASA Jet Propulsion Laboratory's Team-X. The views expressed herein are not necessarily endorsed by the sponsor. 


\section{REFERENCES}

1. M. Gruntman, R. L. McNutt, Jr., R. E. Gold, S. M. Krimigis, E. C. Roelof, G. Gloeckler, P. L. Koehn, W. S. Kurth, and S. R. Oleson, Innovative Interstellar Explorer, $55^{\text {th }}$ International Astronautical Congress, Vancouver, Canada, IAC-04-IAA.3.6.4.07, 2004.

2. M. Gruntman, R. L. McNutt, Jr., R. E. Gold, S. M. Krimigis, E. C. Roelof, J.C. Leary, G. Gloeckler, P. L. Koehn, W. S. Kurth, S. R. Oleson, D. Fiehler, Innovative Explorer Mission to Interstellar Space, 4th IAA Symposium on Realistic Near-Term Advanced Scientific Missions, Aosta, Italy, July 4-6, 2005; J. Brit. Int. Soc., 59, 71-75, 2006.

3. R. L. McNutt, Jr., R. E. Gold, S. M. Krimigis, E. C. Roelof, M. Gruntman, G. Gloeckler, P. L. Koehn, W. S. Kurth, S. R. Oleson, J. C. Leary, D. I. Fiehler, B. J. Anderson, M. Horanyi, and R. A. Mewaldt, Innovative Interstellar Explorer, Proc. Solar Wind 11-SOHO 16, ESA SP-592, 693-696, 2005.

4. R. L. McNutt, Jr., R. E. Gold, S. M. Krimigis, E. C. Roelof, J. C. Leary, M. Gruntman, G. Gloeckler, P. L. Koehn, W. S. Kurth, S. R. Oleson, D. Fiehler, Innovative Interstellar Explorer: Radioisotope Electric Propulsion to the Interstellar Medium, AIAA-2005-4272, 2005 Session 115-EP-25, Mission Systems Analysis, 41st AIAA/ASME/SAE/ASEE Joint Propulsion Conference \& Exhibit, Tucson, Arizona, 13 July 2005.

5. D. I. Fiehler and R. L. McNutt, Jr., Mission design for the Innovative Interstellar Explorer mission, IEPC-2005211, NASA/CR-2005-214017; in press J. Astron. Sci.

6. http://interstellarexplorer.jhuapl.edu, accessed May 21, 2006.

7. L. A. Fisk, Science, 309, 2016-2017 (2005).

8. E. C. Stone, A. C. Cummings, F. B. McDonald, B. C. Heikkila, N. Lal, and W. R. Webber, Science, 309, $2017-$ 2020 (2005).

9. R. B. Decker, S. M. Krimigis, E. C. Roelof, M. E. Hill, T. P. Armstrong, G. Gloeckler, D. C. Hamilton, and L. J. Lanzerotti, Science, 309, 2020-2024 (2005).

10. D. A. Gurnett and W. S. Kurth, Science, 309, 2025-2027 (2005).

11. L. F. Burlaga, N. F. Ness, M. H. Acuna, R. P. Lepping, J. E. P. Connerney, E. C. Stone, and F. B. McDonald, Science, 309, 2027-2029 (2005).

12. W. I. Axford, "The interaction of the solar wind with the interstellar medium", in Solar Wind, edited by C.P. Sonnett, P.J. Coleman, and J.M. Wilcox, NASA Spec. Publ., NASA SP-308, 609-660, 1972.

13. G. P. Zank, Space Sci. Rev., 89, 1-275 (1999).

14. L. D. Jaffe and C. V. Ivie, Icarus, 39, 486-494 (1979).

15. T. E. Holzer, et al. The Interstellar Probe: Scientific objectives for a Frontier mission to the heliospheric boundary and interstellar space, NASA Publication, 1990.

16. R. A. Mewaldt, J. Kangas, S.J. Kerridge, and M. Neugebauer, Acta Astron., 35, Suppl., 267-276 (1995).

17. R. L. McNutt, Jr., R. E. Gold, E. C. Roelof, L. J. Zanetti, E. L. Reynolds, F. W. Farquhar, D. A. Gurnett, and W. S. Kurth, J. Brit. Int. Soc., 50, 463-474 (1997).

18. R. A. Mewaldt, and Liewer, P.A., "Scientific payload for an Interstellar probe mission," The Outer Heliosphere: The Next Frontier, COSPAR Colloquia Series, Vol. 11, K. Scherer, H. Fichtner, H.-J. Fahr, and E. Marsch, eds., Pergamon, New York, 2001, 2001, pp.451-464.

19. P. C. Liewer, Mewaldt, R. A., Ayon, J. A., Garner, C., Gavit, S., and Wallace, R. A., "Interstellar probe using a solar sail: Conceptual design and technological challenges," COSPAR Colloquium on The Outer Heliosphere: The Next Frontiers, COSPAR Colloquia Series, Vol. 11, K. Scherer, H. Fichtner, H.-J. Fahr, and E. Marsch, eds., Pergamon, New York, 2001, pp.411-420.

20. http://interstellar.jpl.nasa.gov/interstellar/probe/introduction/objectives.html, accessed May 22, 2006.

21. R. J. Noble, R. J., Acta Astron., 44, 193-199 (1999).

22. D. I. Fiehler, R. L. McNutt, Jr., "Mission design for the Innovative Interstellar Explorer mission", IEPC-2005-211, NASA/CR-2005-214017; in press J. Astron. Sci.

23. Exploration of the Outer Heliosphere and the Local Interstellar Medium: A Workshop Report, Committee on Solar and Space Physics, Space Studies Board, Division on Engineering and Physical Sciences, National Research Council of the National Academies, The National Academies Press, Washington, D. C., 2004, 56pp. 